\title{
Hubungan Pengetahuan Keluarga Dengan Kepatuhan Pasien Dalam Menjalankan Diet DM Tipe II Di RSUD Sekarwangi Sukabumi
}

\author{
Egi Mulyadi ${ }^{1}$, Burhanuddin Basri ${ }^{2}$ \\ Fakultas Ilmu Keperawatan, Universitas Muhammadiyah Sukabumi ${ }^{1}$ \\ Fakultas Ilmu Keperawatan, Universitas Muhammadiyah Sukabumi ${ }^{2}$ \\ Email: egi,mulyadi2211@gmail.com, burhanganteng720@gmail.com
}

\begin{abstract}
Abstrak. Latar Belakang: DM (Diabetes Mellitus) merupakan kelainan heterogen yang ditandai kenaikan kadar glukosa dalam darah. Dari data awal yang peneliti dapatkan di RSUD Sekarwangi Sukabumi pada tahun 2020 pada bulan Mei pasien yang menderita DM Tipe II sebanyak 189 jiwa, pada bulan Juni sebanyak 213 jiwa, pada bulan Juli sebanyak 200 jiwa, pada bulan Agustus sebanyak 185 jiwa, pada bulan September sebanyak 203 jiwa, dan pada bulan Oktober sebanyak 39 jiwa. Berdasarkan dari hasil wawancara 5 pasien yang menderita DM Tipe II diruang Poli Penyakit Dalam RSUD Sekarwangi Sukabumi didapatkan 3 pasien yang mengatakan tidak mengerti apa yang dimaksud dengan DM Tipe II dan bagaimana tanda dan gejala DM Tipe II. Hal ini dikarenakan kurangnya pengetahuan pasien atau keluarga pasien tentang DM Tipe II dan informasi yang masih kurang pada masyarakat tentang DM Tipe II. Dan 1 pasien dan keluarga pasien mengatakan mengerti apa yang dimaksud dengan DM Tipe II. Tujuan: Untuk mengetahui hubungan pengetahuan keluarga dengan kepatuhan pasien dalam menjalankan diet DM Tipe II. Metode Penelitian: Penelitian ini menggunakan pendekatan kuantitatif dengan rancangan penelitian deskripsi korelasi serta menggunakan rancangan cross sectional. Populasi Dan Sampel: Populasi dalam penelitian 242 pasien dengan sampel 71 responden. Hasil Penelitian: hasil uji chi square menunjukan bahwa nilai $p$ value $0,015<0,05$ yang berarti ada hubungan antara pengetahuan keluarga dengan kepatuhan pasien dalam menjalankan diet DM Tipe II. Kesimpulan: Ada hubungan pengetahuan keluarga dengan kepatuhan pasien dalam menjalankan diet DM Tipe II di RSUD Sekarwangi Sukabumi. Saran: Bagi pasien yang menderita DM Tipe II diharapkan untuk meningkatkan pengetahuan dan mematuhi dalam menjalankan diet DM Tipe II.
\end{abstract}

Kata Kunci: Pengetahuan, kepatuhan diet DM Tipe II

\section{PENDAHULUAN}

Diabetes Melitus (DM) merupakan kelainan heterogen yang ditandai kenaikan kadar glukosa dalam darah. Gejala DM adalah rasa haus (polifagi), peningkatan selera makan (polifagi) dan peningkatan berkemih (poliuri). Penderita DM beresiko terhadap penyakit lain, yakni penyakit jantung, kebutaan, gagal ginjal, ganggren dan gangguan pembuluh darah di otak, gangguan secara psikologis akibat rendahnya penerimaan penderita di masyarakat (Armstrong, \& Lawrence, 2007). Diabetes Mellitus (DM) merupakan keadaan hiperglikemia kronik disertai berbagai kelainan metabolic akibat pengguanaan hormonal, yang menimbulkan berbagai komplikasi kronik pada mata, ginjal, saraf dan pembuluh darah, disertai lesi pada membran basalis dalam dalam pemeriksaan dengan mikroskop elektron (Mansjoer, 2010).

Diabetes Mellitus (DM) merupakan gangguan kesehatan yang berupa kumpulan gejala yang disebabkan oleh peningkatan kadar gula (glukosa) darah akibat kekurangan ataupun resistensi insulin. Penyakit ini sudah lama dikenal, terutama di kalangan keluarga, khususnya keluarga 'berbadan besar' (kegemukan) bersama dengan gaya hidup (Bustan, 2007). Diabetes Mellitus merupakan salah satu penyakit yang prevalensinya terus mengalami peningkatan di dunia, baik pada negara maju ataupun negara sedang berkembang, sehingga dikatakan bahwa Diabetes Melitus sudah menjadi masalah kesehatan atau penyakit global pada masyarakat (Suiraoka, 2012).

Jumlah penderita DM didunia dari tahun ke tahun menunjukan adanya peningkatan. Berdasarkan data dari International Diabetes Federation (IDF 2014). Jumlah penderita DM sebanyak 366 juta jiwa ditahun 2011 meningkat menjadi 387 juta jiwa ditahun 2014 dan diperkirakan akan bertambah menjadi 592 juta jiwa pada tahun 2035 . 
Jumlah kematian yang terjadi pada tahun 2014 sebanyak 4,9 juta jiwa dimana setiap tujuh detik terdapat 1 kematian dari penderita DM didunia. WHO (2013) mengatakan sebanyak $80 \%$ penderitan DM didunia berasal dari negara berkembang salah satunya merupakan Indonesia. Peningkatan jumalah penderita DM yang terjadi secara konsisten menunjukan bahwa penyakit DM merupakan masalah kesehatan yang perlu mendapat perhatian khusus dalam pelayanan kesehatan masyarakat.

Organisasi kesehatan dunia (WHO) memperkirakan Indonesia menduduki kedudukan ke-4 didunia dalam hal jumlah pasien Diabetes Melitus. Indonesia dengan populasi 230 juta penduduk, merupakan negara ke-4 terbesar pasien diabetes setelah China, India dan Amerika Serikat (Xinhua, 2007). Dengan terjadinya ketidakpatuhan pada penderita DM maka akan mengakibatkan kadar gula darah menurun atau meningkat melebihi dari batas normal sehingga akan menimbulkan komplikasi bahkan kematian (IDF, 2013). Untuk meningkatkan kepatuhan pada pasien DM, sangat penting untuk mengetahui mengapa ketidakpatuhan terjadi.

Berdasarkan estinasi data Internasional Diabetes Federatio (IDF), kasus DM di Indonesia pada tahun 2010 menepati urutan keempat tertinggi didunia setelah Cina, India dan Amerika, yaitu 10,4 juta jiwa dan diperkirakan jumlahnya melebihi 21 juta jiwa pada tahun 2025 mendatang. Riskesdas 2018 menunjukkan prevalensi penyakit tidak menular berdasarkan pemeriksaan gula darah, diabetes melitus di Indonesia naik dari 6,9\% menjadi 8,5\% (Riskesdas 2018). Prevalensi Diabetes Melitus di Jawa Barat naik dari 1,3\% menjadi 1,7\% (Kemenkes RI 2018). Peningkatan prevalensi kasus diabetes melitus berjalan seiring dengan peningkatan faktor risiko dari diabetes melitus sendiri (Sornoza, 2011).

Berdasarkan Program Pengendalian Penyakit Tidak Menular Dinkes Kabupaten Sukabumi Tahun 2019 menyatakan bahwa penyakit Diabetes Mellitus selama satu dekade sudah masuk menjadi 10 besar penyakit penyakit tidak menular. Diabetes Melitus ini menempati posisi peringkat kedua dari 10 besar penyakit tersebut adalah penyakit Hipertensi, Diabetes Melitus, Asma, Penyakit Jantung Koroner, Stroke, PPOK, Penyakit Tiroid, Cedera akibat kecelakaan lalu lintas, Osteoporosis dan Obesitas. Adapun jumlah kasus penderita Diabetes Melitus Per Wilayah Kabupaten Sukabumi tahun 2017 menunjukan bahwa terdapat 3 wilayah Kabupaten Sukabumi yang memiliki kasus Diabetes Mellitus tertinggi, yaitu Wilayah I, Wilayah IV dan Wilayah VI dari total kasus 9014 kasus. Wilayah I Kabupaten Sukabumi terdapat 1235 kasus dari total penduduk 496.856 jiwa.

Pengelolahan Diabetes Mellitus salah satunya adalah dengan diet diusahakan untuk dapat memenuhi kebutuhan pasien Diebetes Melitus, sehingga pelaksanaan Diabetes Melitus hendaklah diikuti pedoman 3J (Jumlah, Jadwal, dan Jenis). Diabetes Melitus sering menimbulkan komplikasi yang bersifat menahun (kronis). Pasien Diabetes Melitus yang tidak mendapatkan penanganan yang baik akan mengalami komplikasi (Marliani, 2007).

Bustan (2007) mengatakan faktor risiko secara umum terhadap kejadian DM adalah faktor resiko yang tidak bisa dirubah dan faktor resiko yang bisa dirubah meliputi umur, jenis kelamin dan genetik dan faktor yang bisa dirubah meliputi kebiasaan atau pola makan dan kebiasaan merokok. Penatalaksanaan DM dikenal dengan tiga pilar utama pengolahan, yaitu perencanaan makan, latihan jasmani, farmakologi. Kepatuhan pasien terhadap perencanaan makan merupakan salah satu kendala yang dialami pada pasien DM.

Penderita DM banyak yang merasa tersiksa sehubungan dengan jenis dan jumlah makanan yang di anjurkan (Smeltzer \& Bare, 2009). Penelitian Setyani (2007) gambaran tingkat ketaatan diet bagi pasien tidak patuh menjalankan diet DM. Sebanyak 57\% pasien tidak patuh menjalankan diet yang dianjurkan. Pola diet yang dianjurkan bagi pasien DM adalah makanan yang berserat tinggi. Makanan yang berserat tinggi dapat menbantu 
menurunkan kebutuhan akan insulin karena mempunyai kandungan karbohidrat yang rendah namun tetap menganyangkan. Cara penyerapan glukosa sedikit sehingga kebutuhan insulin normal dan kadar gula darah klien dengan DM tetap terkontrol.

Pasien yang patuh pada diet akan mempunyai kontrol kadar gula darah (glikemih) yang lebih baik, dengan kontrol glikemih yang baik dan terus menerus akan dapat mencegah komplikasi akut dan mengurangi risiko komplikasi jangka panjang.perbaikan kotrol glikemih berhubungan dengan penurunan kejadian kerusakan retina mata (retinopati), kerusakan pada ginjal (nefropati), sebaliknya bagi pasien yang tidak patuh akan mempengaruhi kontrol glikemihnya menjadi kurang baik bahkan tidak terkontrol, hal ini yang akan timbul tidak dapat dicegah (Suryono, 2008).

Terapi dietetik merupakan pilar pengandalian Diabetes Melitus, kepatuhan dalam dalam mejalankan diet menjadi harapan bagi tim kesehatan rumah sakit. Salah satu faktor yang sangat penting bagi penderita DM adalah perilaku hidup sehat. Salah satu hidup sehat cara untuk mencegah komplikasi tersebut adalah memberikan pengetahuan awal tentang upaya pencegahan sekunder pada klien DM (Darusman, 2009). Ada beberapa faktor yang mempengaruhi kepatuhan pasien termasuk kepatuhan dalam melaksanakan program diet pada pasien Diabetes Mellitus yaitu pemahaman tentang instruksi, kualitas interaksi, dukungan sosial keluarga, serta keyakinan, sikap dan kepribadian pasien.

Kepatuhan secara umum didefinisikan sebaga tingkat perilaku seseorang yang mendapatkan pengobatan, mengikuti diet, dan melaksankan gaya hidup sesuai dengan rekomendasi pemberi pelayanan kesehatan. Salah satu wujud kepatuhan pasien adalah dengan cara mengikuti anjuran diet yang disarankan oleh ahli gizi. Ahli gizi rumah sakit memberikan rekomendasi atau saran yang terkait dengan diet yang dianjurkan sesuai dengan penyakit yang diderita pasien tersebut. Ketidakpatuahan pasien dipengaruhi oleh empat faktor yaitu keyakinan, sikap dan kepribadian, pemahaman terhadap instruksi, kelurga dan kualitas terhadap intruksi. Keluarga merupakan pihak yang paling dekat pasien. Keluarga menjadi salah satu kunci seseorang berperilaku. Peran keluarga sangat penting dalam memberikan dukungan dan motivasi kepada pasien sehingga pasien patuh dalam menjalankan terapi. Dukungan emosional seperti memberikan pearhatian, mengingatkan jadwal pengobatan, ataupun menemani pasiensaat beobat dapat meningkatkan kepatuhan pada pasien (Niven, 2002).

Dari data awal yang peneliti dapatkan di RSUD Sekarwangi Sukabumi pada tahun 2020 pada bulan Mei pasien yang menderita DM Tipe II sebanyak 189 jiwa, pada bulan Juni sebanyak 213 jiwa, pada bulan Juli sebanyak 200 jiwa, pada bulan Agustus sebanyak 185 jiwa, pada bulan September sebanyak 203 jiwa, dan pada bulan Oktober sebanyak 39 jiwa (Poliklinik Penyakit Dalam/internist RSUD Sekarwangi Sukabumi, 2020).

Berdasarkan dari hasil wawancara 5 pasien yang menderita DM Tipe II diruang Poli Penyakit Dalam RSUD Sekarwangi Sukabumi didapatkan 3 pasien yang mengatakan tidak mengerti apa yang dimaksud dengan DM Tipe II dan bagaimana tanda dan gejala DM Tipe II. Hal ini dikarenakan kurangnya pengetahuan pasien atau keluarga pasien tentang DM Tipe II dan informasi yang masih kurang pada masyarakat tentang DM Tipe II. Dan 1 pasien dan keluarga pasien mengatakan mengerti apa yang dimaksud dengan DM Tipe II.

Dari hasil uraian diatas peneliti terdorong untuk mengetahui "Hubungan pengetahuan keluarga dengan kepatuhan dalam menjalankan diet Diabetes Melitus tipe II di RSUD Sekarwangi Sukabumi”.

\section{Tujuan Penelitian}

Diketahuinya hubungan pengetahuan keluarga dengan kepatuhan pasien dalam menjalankan diet DM Tipe II di RSUD Sekarwangi Sukabumi.

\section{Desain Penelitian}

Penelitian ini menggunakan pendekatan kuantitatif dengan rancangan penelitian 
deskripsi korelasi serta menggunakan rancangan cross sectional untuk melihat hubungan pengetahuan keluarga dengan kepatuhan dalam menjalankan diet DM Tipe II. Penelitian deskripsi korelasi adalah penelitian yang bertujuan untuk mengetahui adanya hubungan antara dua atau lebih variable (Arikunto, 2009). Metode cross secsional dilakukan dengan cara mengukur variabel independent dan variabel dependent hanya satu kali tanpa dilakukan tindak lanjut serta penelitian dilakukan pada satu waktu (Saryono, 2008).

\section{Populasi, Sampel dan Sampling Penelitian}

1. Populasi

Populasi adalah subjek yang memenuhi kriteria yang telah ditetapkan (Nursalam, 2011). Populasi dalam penelitian ini adalah pasien yang berobat di RSUD Sekarwangi Sukabumi. Jumlah pasien DM Tipe II di RSUD Sekarwangi Sukabumi. adalah 242 pasien.

2. Sampel

Sampel adalah bagian atau jumlah dari karakteritik yang dimiliki oleh populasi tersebut. Bila populasi besar, dan peneliti tidak mungkin mempelajari semua yang ada pada populasi, maka peneliti akan mengambil sampel dari populasi itu. Untuk itu sampel yang diambil dari populasi harus betul-betul representative (Sugiono, 2014). Adapun besarnya sampel yang dibutuhkan dihitung menggunakan rumus Slovin menurut (Notoadmodjo, 2010).

$$
\begin{aligned}
n & =\frac{N}{1+N \cdot d^{2}} \\
n & =\frac{242}{1+242 \cdot(0,1)^{2}} \\
n & =\frac{242}{1+242 \cdot(0,01)^{2}} \\
n & =\frac{242}{1+2,42} \\
n & =\frac{242}{3,42} \\
n & =70,7=71 \text { sampel }
\end{aligned}
$$

3. Sampling

Sampling adalah suatu proses seleksi sampel yang digunakan dalam penelitian dari populasi yang ada (A,Aziz Alimul Hidayat, 2012). Teknik pengambilan sampel dengan cara Purposive Sampling yaitu pengambilan sampel sesuai dengan keinginan peneliti yang sesuai dengan kriteria inklusi dan eksklusi.

\section{Analisa Data}

Metode analisis data yang dilakukan sebagai berikut:

1. Analisis univariat yang dilakukan terhadap tiap variabel dari hasil penelitian dengan menggunakan tabel distribusi frekuensi sehingga menghasilkan distribusi dan persentase setiap variabel penelitian.

2. Analisis bivariat dilakukan untuk menguji hipotesis hubungan antara setiap variabel independen yang diteliti dengan variable dependen. Analisis bivariat akan dilakukan dengan menggunakan uji chi-square. Uji chi-square digunakan untuk mengetahui ada atau tidaknya hubungan dua buah variabel menggunakan program SPSS.

\section{HASIL PENELITIAN DAN PEMBAHASAN}

Penelitian ini menggunakan pendekatan kuantitatif dengan rancangan penelitian deskripsi korelasi serta menggunakan rancangan cross sectional untuk melihat hubungan pengetahuan keluarga dengan kepatuhan dalam menjalankan diet DM Tipe II di RSUD Sekarwangi Sukabumi. Dengan jumlah responden sebanyak 71 responden. Berdasarkan penelitian yang dilakukan didapatkan analisis sebagai berikut

1. Analisa Univariat

a. Karakteristik Responden

Analisis dilakukan sesuai dengan data yang didapatkan dari pasien DM Tipe II meliputi umur, jenis kelamin, pendidikan, dan pekerjaan.

1) Umur

Tabel 5.1. Distribusi Karakteristik Responden Berdasarkan Umur di RSUD Sekarwangi Sukabumi

\begin{tabular}{ccc}
\hline Umur & Jumlah $(\mathrm{F})$ & Persen $(\%)$ \\
\hline $35-39$ & 1 & 1.4 \\
$40-44$ & 12 & 16.9 \\
$45-49$ & 17 & 23.9 \\
$50-54$ & 16 & 22.5 \\
\hline
\end{tabular}


Terakreditasi Peringkat 4 (No. SK: 36/E/KPT/2019)

\begin{tabular}{ccc}
\hline $55-59$ & 12 & 16.9 \\
$60-65$ & 13 & 18.3 \\
\hline Total & 71 & 100.0 \\
\hline
\end{tabular}

Sumber : Data Primer

Berdasarkan tabel 4.1 dari 71 responden menunjukkan bahwa yang berumur 60-65 tahun yang terbanyak 13 responden dengan persentase (18.3\%), sedangkan yang paling sedikit berumur 35-39 tahun 1 responden dengan persentase (1.4\%).

Menurut Sudoyo (2006) umur mempengaruhiresiko dan kejadian DM, umur erat kaitannya dengan kenaikan kadar glukosa darah, sehingga semakin meningkat umur maka prevalensi DM dan gangguan toleransi glukosa semakin tinggi, proses menua yang berlangsung setelah usia 30 tahun mengakibatkan perubahan anatomis, fisiologis dan biokimia, usia 30 tahun, maka kadar glukosa darah akan naik 1-2 $\mathrm{mg} / \mathrm{dl} /$ tahun pada saat puasa dan akan naik 5,6-13 $\mathrm{mg} / \mathrm{dl}$ pada jam setelah makan.

2) Jenis kelamin

Tabel 5.2. Distribusi Karakteristik Responden Berdasarkan Jenis Kelamin di RSUD Sekarwangi Sukabumi

\begin{tabular}{ccc}
\hline $\begin{array}{c}\text { Jenis } \\
\text { Kelamin }\end{array}$ & Jumlah & $\begin{array}{c}\text { Persen } \\
(\%)\end{array}$ \\
\hline Laki-laki & 45 & 63.4 \\
Perempuan & 26 & 36.6 \\
\hline Total & 71 & 100.0 \\
\hline
\end{tabular}

Sumber : Data Primer

Berdasarkan Tabel 4.2 menunjukkan dari 71 responden yang berjenis kelamin laki-laki sebanyak 45 responden dengan persentase $(63.4 \%)$ dan perempuan sebanyak 26 responden dengan persentase $(36.6 \%)$.

3) Pendidikan terakhir

Tabel 5.3. Distribusi Karakteristik Responden Bedasarkan Pendidikan Terakhir di RSUD Sekarwangi Sukabumi

\begin{tabular}{ccc}
\hline $\begin{array}{c}\text { Pendidikan } \\
\text { Terakhir }\end{array}$ & Jumlah $(\mathrm{F})$ & Persen $(\%)$ \\
\hline Tidak Tamat & & \\
SD & 4 & 5.6 \\
SD & 10 & 14.1 \\
SMP & 12 & 16.9 \\
SMA & 20 & 28.2 \\
S1 & 25 & 35.2 \\
\hline Total & 71 & 100.0 \\
\hline
\end{tabular}

\section{Sumber : Data Primer}

Berdasarkan Tabel 4.3 dari 71 responden menunjukkan bahwa yang berpendidikan terakhir S1 yang terbanyak 25 responden dengan persentase $(35.2 \%)$, sedangkan yang paling sedikit yang berpendidikan tidak tamat SD sebanyak 4 responden dengan persentase $(5.6 \%)$.

Tingkat pendidikan memiliki pengaruh terhadap kejadian penyakit DM. orang yang tingkat pendidikannya tinggi biasanya akan memiliki banyak pengeahuan tentang kesehatan. Dengan adanya pengetahuan tersebut orang akan memiliki kesadaran dalam menjaga kesehatannya (Irawan, 2010).

4) Pekerjaan

Tabel 5.4. Distribusi Karakteristik Responden Berdasarkan Pekerjaan di RSUD Sekarwangi Sukabumi

\begin{tabular}{ccc}
\hline Pekerjaan & Jumlah $(\mathrm{F})$ & Persen $(\%)$ \\
\hline PNS & 21 & 29.6 \\
Swasta & 11 & 15.5 \\
Petani & 10 & 14.1 \\
Pedagang & 2 & 2.8 \\
IRT dan Lain-lain & 27 & 38.0 \\
\hline Total & 71 & 100.0 \\
\hline
\end{tabular}

Sumber : Data Primer

Berdasarkan Tabel 4.5 dari 71 responden menunjukkan bahwa yang berpekerjaan IRT yang terbanyak 27 responden dengan persentase $(38.0 \%)$, sedangkan yang paling sedikit pedagang sebanyak 2 responden dengan persentase $(2.8 \%)$.

5) Lama Menderita DM Tipe II

Tabel 5.5. Distribusi Karakteristik Responden

Berdasarkan Pasien Yang Lama

Menderita DM Tipe II di RSUD

Sekarwangi Sukabumi

\begin{tabular}{ccc}
\hline $\begin{array}{c}\text { Lama } \\
\text { Menderita }\end{array}$ & Jumlah $(\mathrm{F})$ & Persen $(\%)$ \\
DM & & \\
\hline 6 Tahun & 6 Tahun & 9.9 \\
5 Tahun & 5 Tahun & 23.9 \\
3 Tahun & 3 Tahun & 11.3 \\
13 Tahun & 13 Tahun & 4.2 \\
7 Tahun & 7 Tahun & 5.6 \\
16 Tahun & 16 Tahun & 4.2 \\
10 Tahun & 10 Tahun & 7.0 \\
\hline
\end{tabular}




\begin{tabular}{crr}
\hline 11 Tahun & 11 Tahun & 1.4 \\
2 Tahun & 2 Tahun & 8.5 \\
14 Tahun & 14 Tahun & 1.4 \\
1 Tahun & 1 Tahun & 4.2 \\
4 Tahun & 4 Tahun & 12.7 \\
15 Tahun & 15 Tahun & 2.8 \\
8 Tahun & 8 Tahun & 2.8 \\
\hline Total & 71 & 100.0 \\
\hline
\end{tabular}

Sumber : Data Primer

Berdasarkan Tabel 4.5 dari 71 responden menunjukkan bahwa yang lama menderita DM selama 16 tahun berjumlah 3 responden denga persentase (4.2\%), sedangkan yang tidak lama menderita DM selama 1 tahun berjumlah 3 responden dengan persentase $(4.2 \%)$.

Lama mengalami DM Tipe II seringkali kurang menggambarkan proses penyakit sebenarnya. Hal ini karenakan banyak sekali pasien DM Tipe II yang baru terdiagnosa pada saat telah nmengalami komplikasi, padahal proses perjalanan penyakit telah berlangsung bertahun-tahun sebelumnya namun terdiagnosa (Arianti, 2011).Pengetahuan

Tabel 5.6. Distribusi Karakteristik Responden Berdasarkan Pengetahuan di RSUD Sekarwangi Sukabumi

\begin{tabular}{ccc}
\hline Pengetahuan & Jumlah $(\mathrm{F})$ & Persen $(\%)$ \\
\hline Baik & 21 & 29.6 \\
Cukup & 33 & 46.5 \\
Kurang & 17 & 23.9 \\
\hline Total & 71 & 100.0 \\
\hline
\end{tabular}

Sumber : Data Primer

Berdasarkan Tabel 4.6 yang didapatkan menunjukkan dari 71 responden yang berpengetahuan baik berjumlah 21 responden dengan persentase (29.6\%), yang pengetahuan cukup berjumlah 33 responden dengan persentae (46.5\%), sedangkan berpengetahuan kurang yaitu 17 responden dengan persentase $(23.9 \%)$.

Menurut Notoatmodjo (2003) bahwa pengetahuan merupakan domain dari perilaku yang sangat penting untuk terbentuknya tindakan seseorang. Begitu juga pengetahuan yang dimiliki oleh pasien DM Tipe mengenai manfaat terapi serta komplikasi yang mungkin terjadi diharapkandapat membentuk perilaku yang positif, salah satunyakepatuhan dalam melaksanakan 4 (empat) pilar penatalaksanaan DM dirumah.

6) Kepatuhan

Tabel 5.7. Distribusi Karakteristik Responden Berdasarkan Kepatuhan di RSUD Sekarwangi Sukabumi

\begin{tabular}{ccc}
\hline Kepatuhan & Jumlah $(\mathrm{F})$ & Persen \\
\hline Patuh & 44 & 62.0 \\
Tidak Patuh & 27 & 38.0 \\
\hline Total & 71 & 100.0 \\
\hline & Sumber : Data Primer
\end{tabular}

Berdasarkan Tabel 4.7 dari 71 responden menunjukkan bahwa yang patuh berjumlah 44 responden dengan persentase $(62.0 \%)$, sedangkan yang tidak patuh berjumlah 27 responden dengan persentase $(38.0 \%)$.

Kepatuhan dimaknai sebagai perilaku sebagai seseorang dalam meminum obat, mengikuti anjuran diet dan atau melakukan perubahan gaya hidup yang sesuai dengan rekomendasi dari tenaga kesehatan professional.

Ketidakpatuhan dapat mendangkan beberapa konsekuensi yang harus ditangguang individu. Beberapa konsekuensi yang harus ditanggung individu mungkin tidak risakan secara langsung, namun dampak serius akibat sikap tidak patuh mampu memberikan efek dikemudian waktu (Saifunurmazah, 2013).

\section{Analisa Bivariat}

Tabel 5.8. Hubungan Pengetahuan Keluarga Dengan Kepatuhan Pasien Dalam Menjalankan Diet DM Tipe II di RSUD Sekarwangi Sukabumi

\begin{tabular}{|c|c|c|c|c|c|c|c|}
\hline \multirow[t]{3}{*}{ Pengetah } & \multicolumn{4}{|c|}{ Kepatuhan Diet DM } & \multicolumn{2}{|c|}{ Total } & \multirow[t]{2}{*}{$\begin{array}{c}\mathbf{P} \\
\text { Value }\end{array}$} \\
\hline & \multicolumn{2}{|c|}{ Patuh } & \multicolumn{2}{|c|}{ Tidak Patuh } & & & \\
\hline & $\mathbf{F}$ & $\%$ & $\mathbf{F}$ & $\%$ & $\mathbf{F}$ & $\%$ & 0,015 \\
\hline Baik & 18 & 25,4 & 3 & 4,2 & 21 & 29,6 & \\
\hline Cukup & 19 & 26,8 & 14 & 19,7 & 33 & 46,5 & \\
\hline Kurang & 7 & 9,9 & 10 & 14,1 & 17 & 23,9 & \\
\hline Total & 44 & 62,0 & 27 & 38,0 & 71 & 100 & \\
\hline
\end{tabular}

Sumber : Data Primer

Dari table 4.8 menunjukkan hubungan antara pengetahuan dengan kepatuhan diet DM Tipe II yang berkunjung di Poli Penyakit 
Dalam di RSUD Sekarwangi Sukabumi. Dari 21 responden DM Tipe II yang mempunyai pengetahuan baik sebanyak 18 yang mematuhi diet DM Tipe II. Dari pengetahuan cukup sebanyak 33 responden, yang mematuhi diet DM Tipe II sebanyak 19 responden. Sedangkan yang berpengetahuan kurang sebanyak 17 responden, dan yang mematuhi diet DM Tipe II sebanyak 7 responden.

Uji bivariat dengan menggunakan uji Chi-square digunakan untuk melihat hubungan antara pengetahuan keluarga dengan kepatuhan pasien dalam menjalani diet DM Tipe II. Dari hasil yang didapatkan diperoleh ada hubungan pengetahuan keluarga dengan kepatuhan pasien dalam menjalankan diet DM Tipe II di RSUD Sekarwangi Sukabumi. Dengan uji Chi Square dengan hasil ( $p$ value $0,015<0,05$ ) menunjukan bahwa ada hubungan pengetahuan keluarga dengan kepatuhan pasien dalam menjalankan diet DM Tipe II di RSUD Sekarwangi Sukabumi.

Penelitian ini sejalan dengan penelitian sebelumnya yang dilakukan oleh Abdurahim Senuk (2013) tentang Hubungan Pengetahuan dan Dukungan Keluarga Dengan Kepatuhan Menajalankan Diet Diabetes Melitus Di Poliklinik RSUD Kota Tidore Kepulauan Provinsi Maluku Utara. Penelitian ini adalah penelitian observasional analitik dengan menggunakan desain penelitian Cross Sectional. Informasi dan data penelitian ini dikumpulkan satu kali pada waktu yang bersamaan. Penelitian ini dilaksanakan pada tanggal 7 sampai 21 juni 2013, penelitian ini dilakukan di Poliklinik RSUD Kota Tidore Kepulauan Maluku Utara. Distribusi hubunga pengetahuan denga kepatuhan diet diabetes mellitus menunjukan bahwa dari 20 responden dengan pengetahuan yang baik dan yang patuh dalam menjalankan diet diabetes mellitus 15 orang $(75 \%)$ sedangkan 5 orang lainnya (25\%) tidak patuh dalam menjalankan diet diabetes mellitus. Responden dengan pengetahuan kurang baik dan patuh dalam menjalankan diet diabetes mellitus berjumlah 22 orang $(44,9 \%)$ dan yang tidak patuh dalam menjalankan diet diabetes mellitus berjumlah
27 orang $(55,1 \%)$ dari 49 responden. Pengambilan sampel menggunakan teknik purposive sampling. Dengan uji statistic yang digunakan yaitu uji Chi-Square (x2) tingkat kemagnaan $95 \%$ menunjukan nilai 0,023 . Nilai ini lebih kecil dari nilai 0,05 menunjukan bahwa terdapat hubungan antara pengetahuan dengan kepatuhan menjalani diet diabetes mellitus.

Hal ini sesuai dengan penelitian yang dilakukan Nasrul Hadi Purwanto (2011) dengan judul "Hubungan pengetahuan tentang diet diabetes mellitus dengan kepatuhan pelaksanaan diet pada penderita diabetes mellitus" yang menyatakan bahwa ada hubungan bermakna antara pengetahuan tentang diet diabetes mellitus dengan kepatuhan pelaksanaan diet pada penderita diabetes mellitus dengan kepatuhan pelaksanaan diet pada penderita diabetes mellitus Di RSUD Poso dr. H Moh Anwar Sumenep. Hasil ini diperkuat dengan uji korelasi spearman (rho) didapatkan nilai signifikasi sebesar 0,000 dengan nilai korelasi sebesar 0,817.Maka hipotesis penelitian H0 ditolak dan $\mathrm{H} 1$ diterima yang berarti terdapat hubungan yang bermakna anatara pengetahuan tentang diet diabetes mellitus dengan kepatuhan pelaksanaan diet pada penderita diabetes mellitus Di RSUD dr. H Moh Anwar Sumenep.

Menurut asumsi peneliti responden yang berpengetahuan baik tapi masih tidak patuh dikarenakan responden tidak peduli atau acuh tak acuh dalam proses menjalankan diet DM, responden yang berpengetahuan cukup tapi tidak patuh di karenakan responden tersebut tidak dapat mengontrol pola makan yang baik, serta kurangnya dukungan ataupun motivasi dari keluarga, dan responden yang berpengetahuan kurang tapi masih patuh dikarenakan responden tersebut sadar bahwa penyakit DM akan berdampak buruk ataupun terjadi komplikasi jika tidak mematuhi diet DM Tipe II.

Adapun faktor lainnya yaitu responden lalai karena di akibatkan kebiasaan hidup yang sudah membudaya sehingga tampa dia sadari kegiatan yang dapat membatalkan diet DM Tipe II yang dia lakukan, penyebab 
lainnya biasanya kesibukan dari responden yang memiliki pekerjaan sehingga responden tidak patuh dalam menjalankan diet DM Tipe II.

\section{DAFTAR PUSTAKA}

A.Azis Alimul Hidayat \& Musrifatul Uliyah. ( 2012 ). Buku Ajar Kebutuhan Dasar Manusia. Surabaya : Health Books Publishing.

Ariani, Y. (2011). Hubungan Antara Motivasi dengan Efikasi Diri Pasien DM Tipe 2 Dalam Konteks Asuhan Keperawatan Di RSUP.H.Adam Malik Medan. Tesis. Depok.: Fakultas Ilmu Keperawatan, Universitas Indonesia.

Armstrong, David G., and Lawrence A. Lavery. (2007). "Diabetic foot ulcers: prevention, diagnosis and classification." American family physician 57.6

Darusman, (2009). Perbedaan Perilaku Pasien Diabetes Mellitus Pria dan Wanita dalam Mematuhi Pelaksanaan Diet. Diakses mei 2013.http://beritakedokteranmasyar akat.org/index.php/BKM/article/vie w/159

International Diabetes Federation (IDF). (2013). IDF Diabetes Atlas. 6th ed. p. $11-3$

International Diabetes Federation [IDF]. (2014). IDF Diabetes ATLAS 4th Edition. ISBN-13: 978-2-93022971-3. ADA.

Irawan, D. (2010). Prevalensi dan Faktor Risiko Kejadian Diabetes Melitus Tipe 2 di Daerah Ubran Indonesia (Analisa Data Sekunder Riskesdas 2007). Tesis. Fakultas Kesehatan Masyarakat Indonesia. Jakarta. Available from http://www.lontar.ui.id/[accessed 26 Maret 2015].

Kementrian Kesehatan RI. (2018). Jumlah penderita diabetes indonesia rangking ke-4 di dunia. Jakarta: Kemenkes RI.
Kementrian Kesehatan RI. 2018. Profil Kesehatan Indonesia 2017. Jakarta: Kemenkes RI. Diakses pada tanggal 31 Januari 2019 darihttp://www.depkes.go.id/resour ces/download/pusdatin/profilkesehatanindonesia/ProfilKesehatan-Indonesia-tahun2017.pdf.

Mansjoer, Arif. (2010). Kapita Selekta Kedokteran. Media Aescukapius Jakarta : FKUI.

Niven, N. 2002. Psikologi Kesehatan Pengantar Untuk Perawat \& Profesional Kesehatan Lain. Penerbit Buku Kedokteran EGC. Jakarta.

Notoatmodjo, S. (2003). Ilmu perilaku kesehatan. Jakarta: Rineka.

Notoatmodjo, S. (2010). Metodologi Penelitian Kesehatan. Jakarta : Rineka Cipta.

Nursalam. (2011). Konsep dan penerapan metodologi penelitian ilmu keperawatan. Jakarta : Salemba Medika.

Purwanto, Nasrul Hadi, (2011), Hubungan Pengetahuan Tentang Diet Diabetes Mellitus Dengan Kepatuhan Pelaksanaan Diet Pada Penderita Diabetes Mellitus, Jurnal Keperawatan, Volume 01, Nomor 01, Januari - Desember 2011.

Riset Kesehatan Dasar (Riskesdas) (2018). Badan Penelitian dan Pengembangan Kesehatan Kementerian RI tahun 2018. http://www.depkes.go.id/resources/ download/infoterkini/materi_rakorp op_2018/Hasil\%20Riskesdas\%202 018.pdf - Diakses Agustus 2018.

Saifunurmazah D., (2013). Kepatuhan Penderita Diabetes Mellitus Dalam Menjalani Terapi Olahraga Dan Diet, Skripsi, Fakultas Ilmu Pendidikan, Universitas Negeri Semarang, Semarang.

Saryono. (2008). Metodologi penelitian kesehatan: penuntun praktis bagi pemula. Mitra Cendikia: Jogjakarta. 
Senuk, Abdurrahim. (2013). Hubungan pengetahuan dan dukungan keluarga dengan kepatuhan menjalani diet diabetes mellitus di poliklinik RSUD kota Tidore Kepulauan Provinsi Maluku Utara. Jurnal Keperawatan. Vol 1, No 1. $1-7$.

Setyani. (2007). Hubungan Antara Pengetahuan Dan Sikap Tentang Diabetes Mellitus Dengan Kepatuhan Dalam Melaksanakan Diet Pada Pasien Diabetes Mellitus Di BRSD RSU RAA Soewondo Kabupaten Pati. Skripsi : Tidak dipublikasikan.

Smeltzer, S.C., Bare, B.G., Hinkle, J.L., Cheever, K.H. (2009). Texbook of medical surgical nursing. 12th Edition. Philadelphia: Lipincott Williams \& Wilkins.

Sornoza O., Ariana K., Mendoza S., Humberto D., 2012. Diabetes Mellitus y sus Complicaciones en los Pacientes Atendidos en la Unidad Médica Universitaria de Portoviejo Mayo Septiembre 2011. Diakses pada 27 maret 2013. http://repositorio.utm.edu.ec/handle /123456789/405

Sudoyo, S. (2006). Buku ajar ilmu penyakit dalam. (Edisi 3). Jakarta: Departemen Penyakit Dalam FK UI.

Sugiyono. (2014). Metode Penelitian Pendidikan Pendekatan Kuantitatif, Kualitatif, dan R\&D. Bandung: Alfabeta.

Suiraoka, (2012). Penyakit Degeneratif Menenal, Mencegah dan mengurangi Faktor Risiko 9 Penyakit,Yogyakarta : Nuha Medika.

WHO. (2013). Adherencelong term therapy: Evidence for action. Diakses tanggal 20 Mei 2015, dari http://www.emro.who.int/ncd/publi city/adherencereportindiabetespatie $\mathrm{nt} /$.
Xinhua. (2007). Indonesia Ranks 4th in Terms of Diabetes Sufferers. English. 